Check for updates

Cite this: RSC Adv., 2019, 9, 40301

Received 4th October 2019

Accepted 17th November 2019

DOI: $10.1039 / c 9 r a 07926 b$

rsc.li/rsc-advances

\section{D interconnected nitrogen-self-doped carbon aerogels as efficient oxygen reduction electrocatalysts derived from biomass gelatin $\uparrow$}

\author{
Haoqi Yang, ${ }^{\text {ab }}$ Shuqing Kou, (D) *a Zhiyuan Li, ${ }^{\text {b }}$ Zhiyong Chang, ${ }^{\mathrm{b}}$ Mi Wang, ${ }^{\mathrm{b}}$ \\ Zhenning Liu*b and Guolong Lu (D)*b
}

\begin{abstract}
Development of efficient metal-free electrocatalysts derived from biomass with high activity towards oxygen reduction reaction (ORR) has gained significance attention due to their low manufacturing cost, environmental friendliness and easy large-scale production. Hence, we present a facile method to prepare nitrogen-self-doped carbon aerogels (NSCAs) with a three-dimensional (3D) interconnected porous structure and large surface area. The sample is prepared via high-temperature pyrolysis using gelatin as precursor and sodium chloride $(\mathrm{NaCl})$ as sacrificial template. The obtained NSCA-800 catalyst shows excellent ORR performance in $\mathrm{O}_{2}$-saturated alkaline electrolyte, which is comparable to a commercial Pt/C catalyst, in terms of its onset potential ( $0.92 \mathrm{~V}$ vs. RHE), half-wave potential $(0.77 \mathrm{~V}$ vs. $\mathrm{RHE})$, and limited current density $\left(5.31 \mathrm{~mA} \mathrm{~cm}{ }^{-2}\right)$. Particularly, the NSCA-800 catalyst exhibits outstanding long-term stability, its ORR kinetic current still retains $95.7 \%$ after a continuous $4 \mathrm{~h}$ test while that for commercial Pt/C retains just $74.3 \%$. The sustainable biomass gelatin is a promising precursor for the development of carbon materials as effective ORR catalysts.
\end{abstract}

\section{Introduction}

Highly efficient catalysts for oxygen reduction reaction (ORR) have attracted significant focus and research in metal-air batteries and fuel cells. ${ }^{1-3}$ However, the sluggish kinetics of the ORR is the main bottleneck for commercial applications., ${ }^{\mathbf{4}, 5}$ Until now, platinum (Pt) and Pt-based alloys have been regarded as the most efficient ORR catalysts due to their low overpotential and high current density.$^{6-8}$ Unfortunately, the development of Pt-based electrocatalysts in metal-air batteries and fuel cells is severely restricted due to a few disadvantages, such as expensive cost, scarce resources, and poor long-term stability. Therefore, considerable research has been focused on the preparation of cost-efficient alternatives, such as nonprecious metals ${ }^{\mathbf{9}, 10}$ and even metal-free ORR catalysts, ${ }^{11-13}$ to replace Pt and Pt-based catalysts.

In this regard, heteroatom-doped carbon-based materials, including graphene, ${ }^{14}$ carbon nanofiber, ${ }^{15}$ and carbon nanotube, ${ }^{\mathbf{1 6}}$ have received great attention because of their abundant $\pi$ electrons, relatively low cost, and superior durability. Since

${ }^{a}$ Roll Forging Research Institute, College of Material Science and Engineering, Jilin University, Changchun, Jilin Province, 130022, P. R. China. E-mail: kousq@jlu.edu.cn ${ }^{b}$ Key Laboratory of Bionic Engineering (Ministry of Education), College of Biological and Agricultural Engineering, Jilin University, Changchun, Jilin Province, 130022, P. R.China.E-mail: liu_zhenning@jlu.edu.cn; Guolonglu@jlu.edu.cn

† Electronic supplementary information (ESI) available. See DOI: 10.1039/c9ra07926b
Dai et al. firstly reported nitrogen-doped carbon nanotubes (NCNTs) with outstanding ORR activity in $2009,{ }^{17}$ plenty of heteroatom-doped carbon materials have been studied as metal-free ORR electrocatalyst. ${ }^{\mathbf{1 8 - 2 0}}$ For instance, Geng et al. synthesized nitrogen-doped graphene as highly efficient ORR electrocatalyst in alkaline media, which electrocatalytic overpotential and stability are even better than the $\mathrm{Pt} / \mathrm{C}$ electrocatalyst. ${ }^{21}$ Despite there are some remarkable development on electrocatalytic activity for N-doped CNTs and graphene catalysts, it still has some limitations such as complex chemical treatment and particularly severe agglomeration phenomenon.

In order to obtain electrocatalysts with resource-rich, low cost and environmental friendliness, biomass-derived carbon has regarded as an attractive candidate in electrocatalysis field. In recent years, a large number of studies have concentrated on exploring and developing biomass-derived carbon nanomaterials in the field of ORR, such as corn stover, ${ }^{22}$ ginkgo leaves, ${ }^{23}$ chitosan, ${ }^{24}$ coconut-shell, ${ }^{25}$ cellulose, ${ }^{26}$ and so on. However, there are still two drawbacks in the design and preparation for biomass-derived carbon electrocatalysts. Firstly, it is the common strategy that pyrolysis precursors under $\mathrm{NH}_{3}$ atmosphere or with rich nitrogen materials (e.g. melamine), which is difficult to scale-up production due to the complex process and high cost. Secondly, $\mathrm{KOH}$ is usually used as activated agent to produce porous structure and increase specific surface area for carbon materials, but the overall chemical activation procedure is harmful to equipment, which also decreases the scaling potential. As a consequence, developing 
a novel process to prepare biomass-derived nitrogen-self-doped carbon without any activation technique is immensely important for highly efficient electrocatalysts.

So far, compared with commonly used plant-based biomass materials mentioned above, the biomass materials extracted from animals could contain larger amounts of proteins and higher content of nitrogen. ${ }^{27,28}$ Typically, gelatin is composed of proteins and peptides with high average nitrogen content of $16 \%,{ }^{29}$ which could be produced from hydrolysis collagen and skin, boiling crushed bones and connective tissues. ${ }^{30}$ Therefore, it may be an excellent candidate precursor for nitrogen selfdoped carbons catalysts due to naturally abundant and commercially available. Taking into account its low-cost and high nitrogen content, herein, we fabricate three-dimensional (3D) interconnected nitrogen-self-doped carbon aerogels (NSCAs) derived from biomass gelatin via a NaCl template. The sodium chloride $(\mathrm{NaCl})$ sacrificial template in biomass precursors under pyrolysis process can form porous structure, increase the specific surface area, and promote the mass transfer.

\section{Results and discussion}

The preparation process for 3D interconnected nitrogen-selfdoped carbon aerogel samples is illustrated in scheme 1, including three-step procedures of sol-gel method (step I), pyrolysis (step II) and template removal (step III). In step I, the $\mathrm{NaCl}$ crystal particles were coated with homogeneous biomass gelatin hydrogel. Next, the hydrogel was pyrolyzed at high temperature, which caused the formation of $\mathrm{NaCl}$ crystal particle coated by interconnected carbon aerogels (step II). After removing the $\mathrm{NaCl}$ sacrificial template via deionized water washing, 3D interconnected structure was easily obtained (step III). The samples annealed at $700{ }^{\circ} \mathrm{C}, 800{ }^{\circ} \mathrm{C}$, and $900{ }^{\circ} \mathrm{C}$ were denoted as NSCA-700, NSCA-800, and NSCA-900, respectively.

The surface morphology and structure for the NSCA-800 sample was investigated by using FE-SEM, TEM and HR-TEM measurements. As clearly depicted in Fig. 1a and b, the direct carbonization for gelatin aerogel with $\mathrm{NaCl}$ template led to the formation of abundant pores distributed irregularly in NSCA800 sample. Moreover, from the FE-SEM images of NSCA-700 (Fig. S1 $\dagger$ ) and NSCA-900 (Fig. S2 $\dagger$ ), the as-formed rough, porous and interconnected networks were also observed, which implies the important role of the $\mathrm{NaCl}$ sacrificial template. In addition, the detailed structure for NSCA-800 sample was depicted by TEM (Fig. 1c) and HR-TEM (Fig. 1d), respectively. The TEM result also reveals the 3D interconnected network feature, which could facilitate the electrolyte transport and charge transfer. ${ }^{31}$ The high-resolution transmission electron microscopy (HRTEM) image is depicted in Fig. 1d, which illustrates that the as-formed NSCA-800 catalyst exhibits amorphous structure in interior wrapped by multi-layers of highly curved graphitic shells. The structural distortions and dislocation defects exist in carbon structure is mainly ascribed to the incorporation of nitrogen atoms, which could regard as active sites in ORR process. ${ }^{32}$ Additionally, the element mapping (Fig. 1e-h) obviously indicate that carbon, oxygen and nitrogen elements are homogeneously distributed throughout the $3 \mathrm{D}$ interconnected skeleton. The observed porous carbon skeleton containing nitrogen could provide abundant active sites and ensure superior electrocatalytic activity.

The X-ray diffraction (XRD) patterns was employed to certify the formation of graphitic phases and disordered structure. As illustrated in Fig. 2a, there are two characteristic peaks exist at about $25.4^{\circ}$ and $44.1^{\circ}$ in all three samples, corresponding to the C (002) and (100) lattice planes of graphitic carbon, respectively. ${ }^{33}$ The broad stacking-related (002) diffraction peak at 22$28^{\circ}$ indicates that NSCA samples comprised primarily in amorphous structures, regardless of the pyrolysis temperature. ${ }^{30,34}$ The above results are in agreements with the HR-TEM results (Fig. 1d). To further study the disordered structures and defect sites of three NSCAs samples, the Raman spectroscopic analysis was employed. In general, Raman spectrum for carbon materials consists of two prominent components of " $D$ " and "G" peaks. It is well known that the $\mathrm{D}$ band is $\mathrm{sp}^{3}$ defects and disorder sites, corresponding the vacancy and heteroatoms; and the $\mathrm{G}$ band is $\mathrm{sp}^{2}$-hybridized graphitic carbon, corresponding the graphitic carbon-lattice-structure. ${ }^{35}$ Furthermore, the amount of structural defects and exposed edge planes, which caused by hetero-atom incorporation, could be indicated by calculating the intensity ratio of the D peak to the G peak $\left(I_{\mathrm{D}} / I_{\mathrm{G}}\right)$. As depicted in Fig. $2 \mathrm{~b}$, the calculated $I_{\mathrm{D}} / I_{\mathrm{G}}$ ratio for NSCA-700, NSCA-800 and NSCA-900 are 1.055, 1.054 and 1.052, respectively. The large $I_{\mathrm{D}} / I_{\mathrm{G}}$ ratio indicates that there are abundant structural defects and exposed edge planes exist in NSCA samples. ${ }^{25,36}$

To further obtain the detail information of specific surface areas $\left(S_{\mathrm{BET}}\right)$ and pore size distributions (PSD), $\mathrm{N}_{2}$ adsorptiondesorption isotherms for the NSCA-700, NSCA-800 and NSCA900 samples were measured. As clearly presented in Fig. 3a,

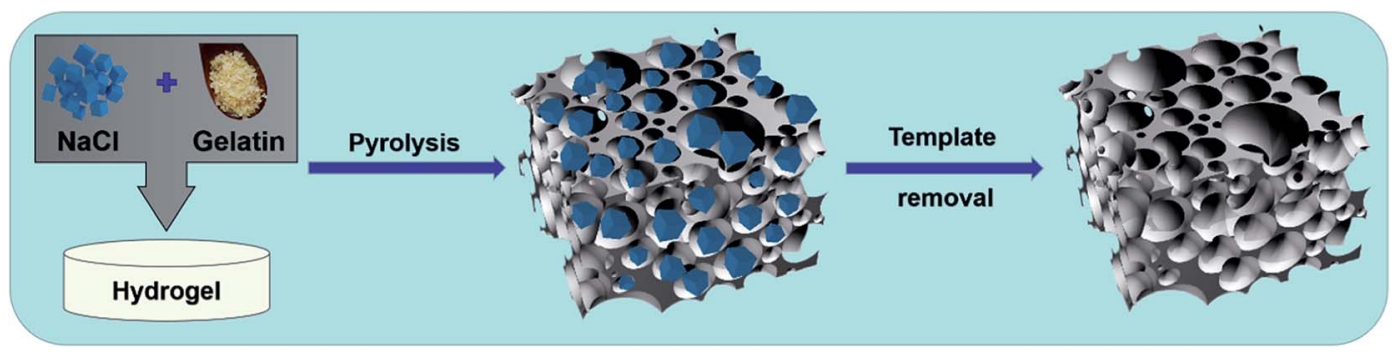

Scheme 1 Synthetic procedure for biomass gelatin-derived 3D interconnected nitrogen-self-doped carbon aerogels (NSCAs). 

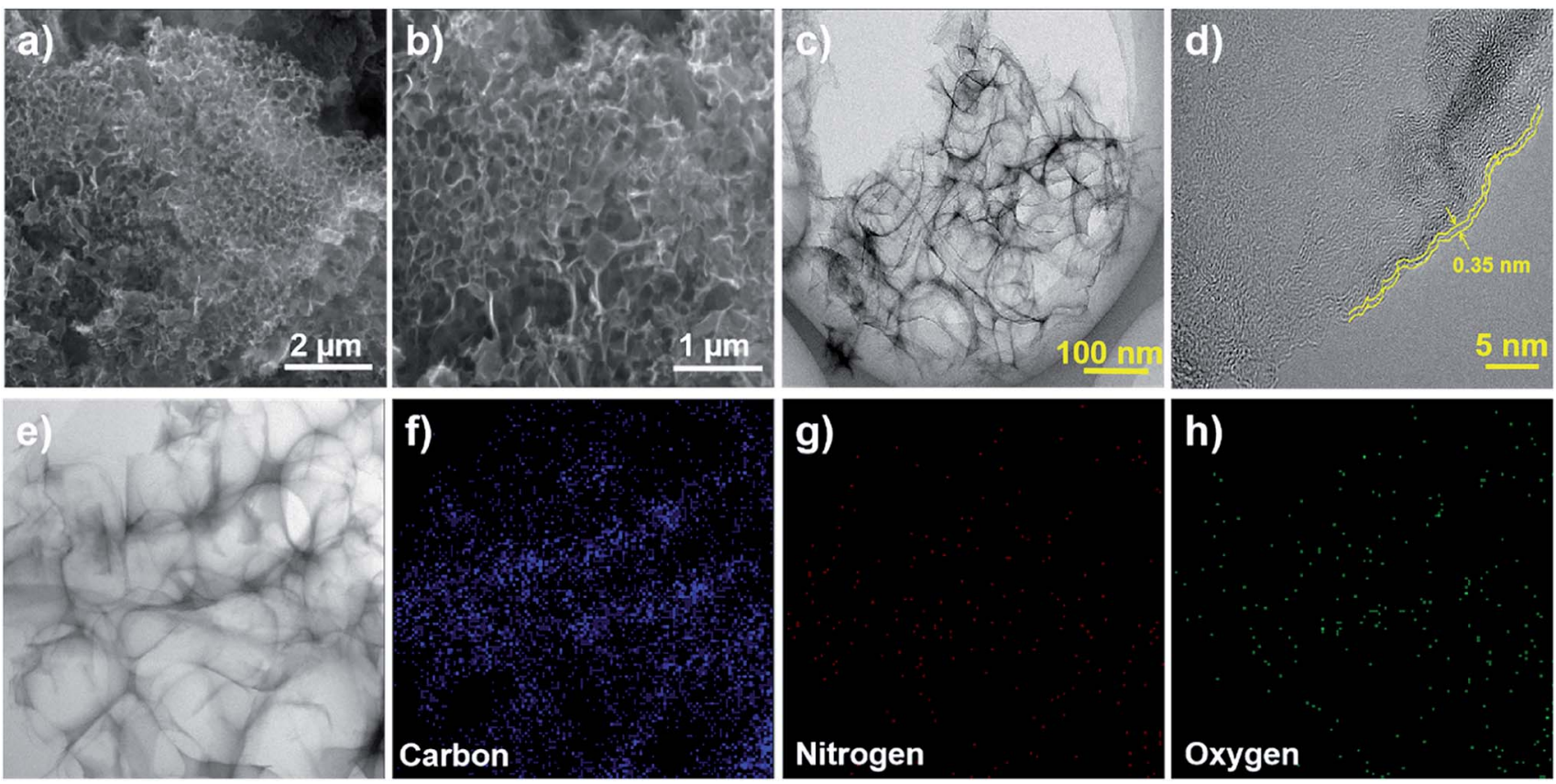

Fig. 1 ( $a$ and $b$ ) The FE-SEM images of NSCA-800. (c and d) The TEM and HRTEM images of NSCA-800, respectively. (e-h) Element mapping of carbon, nitrogen, and oxygen, respectively.

all the NSCA samples display type IV isotherm curves with a large slope at higher relative pressures, which indicates their mesoporous structure. ${ }^{37}$ From the Brunauer-Emmett-Teller (BET) specific surface areas results, as shown in Table $\mathrm{S} 1, \uparrow$ the specific surface areas for NSCA-700, NSCA-800, and NSCA-900 are 376,839 , and $795 \mathrm{~m}^{2} \mathrm{~g}^{-1}$, respectively. Such high specific surface areas could not only expose more active sites, but also improve the ORR electrocatalytic performance due to the facilitated mass transfer and $\mathrm{O}_{2}$ molecules adsorption. ${ }^{38}$ Meanwhile, the PSD of NSCA-700, NSCA-800, and NSCA-900 samples were determined by using Barrett-Joyner-Halenda (BJH) desorption method, as depicted in Fig. 3b. Obviously, the NSCA-800 and
NSCA-900 sample show a relatively broad mesopore distribution, with an average pore size of $\sim 8.4 \mathrm{~nm}$, which is higher than that of NSCA-700 sample. The total pore volumes for NSCA-700, NSCA-800, and NSCA-900 are about $0.34,0.67$ and $0.64 \mathrm{~cm}^{3} \mathrm{~g}^{-1}$, respectively (Table $\mathrm{S} 1 \dagger$ ). Generally, biomass-derived carbon ORR catalysts with high $\mathrm{S}_{\mathrm{BET}}$ and abundant porosity were usually obtained by physical or chemical activation. Such conventional activation methods often require toxic or corrosive chemicals and reagents $(\mathrm{KOH})$, which inevitably increases the cost and decreases the potential of scaled production. However, the biomass gelatin-derived carbon materials with high $S_{\mathrm{BET}}$ and porous structure were successfully prepared with no
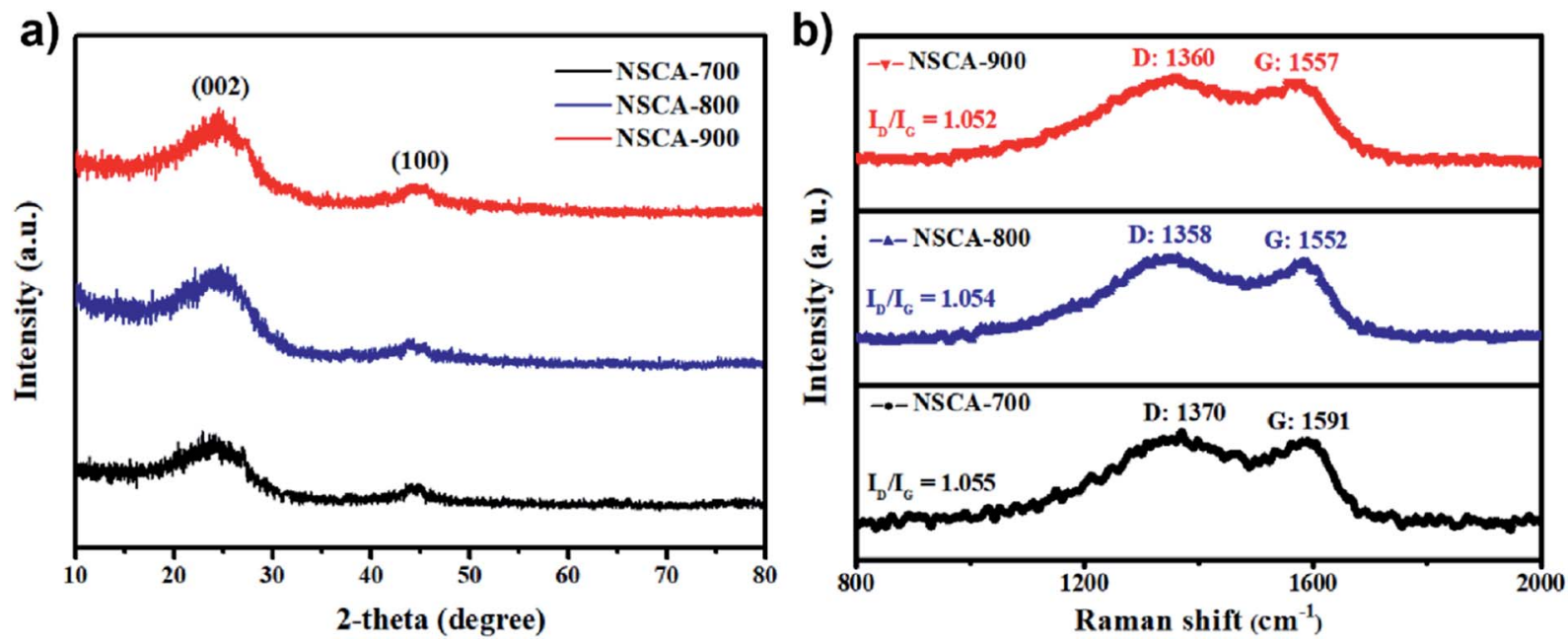

Fig. 2 (a) The XRD patterns, (b) the Raman micro-spectroscopy for the as-prepared NSCA-700, NSCA-800 and NSCA-900 sample, respectively. 

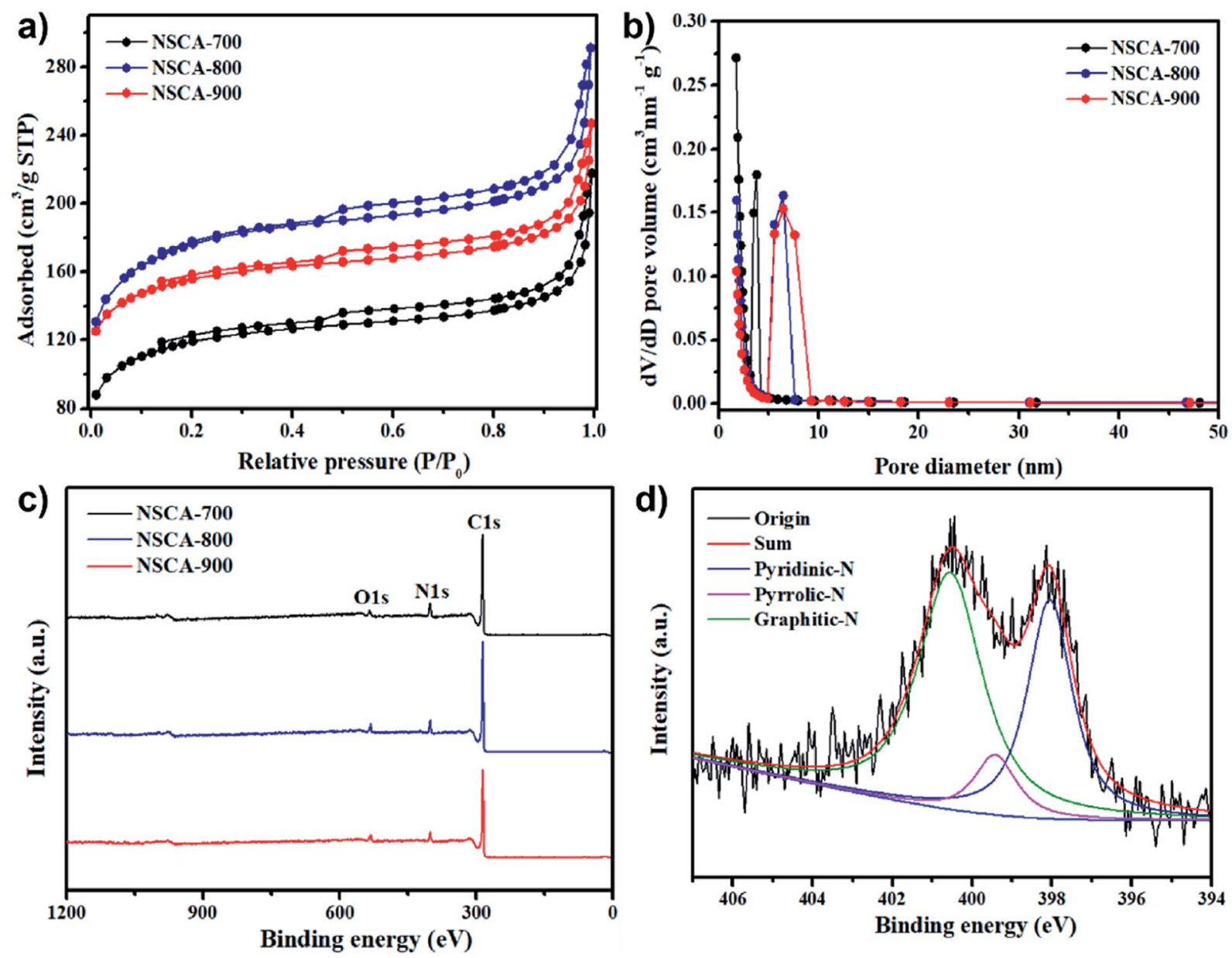

Fig. 3 (a) Nitrogen adsorption-desorption isotherms for the NSCA-700, NSCA-800 and NSCA-900 samples. (b) Pore size distribution curves for the NSCA-700, NSCA-800 and NSCA-900 samples. (c) XPS survey spectra of the NSCA-700, NSCA-800 and NSCA-900 samples. (d) The highresolution $N$ 1s spectra of NSCA- 800 sample.

activation, which could simplify the procedure, lower the cost and promote the fabrication.

To analyze the valence states and stoichiometric composition, X-ray photoelectron spectroscopy (XPS) measurement was carried out. As obviously observed in Fig. 3a, the XPS survey spectra of all three samples exhibit only C1s ( $c a .285 \mathrm{eV})$, N1s (399 eV), and O1s (531 eV) electrons, which confirms the successful incorporation of nitrogen and oxygen into the carbon skeleton. In addition, based on the integrated peak areas, the contents of $\mathrm{C}, \mathrm{N}$ and $\mathrm{O}$ elements are presented in Table S1. $\dagger$ The content for nitrogen in the NSCA-700 sample was estimated to be 5.73 at $\%$, while 5.03 at $\%$ for NSCA-800, and 4.69 at $\%$ for NSCA-900, indicating that the nitrogen content gradually decreased with increasing carbonization temperature. Furthermore, the chemical bonding states of doped nitrogen could be probed by high-resolution scans. As depicted in Fig. 3d, the deconvoluted $\mathrm{N}$ 1s photoelectron envelope for NSCA-800 sample is presented. As comparison, the deconvoluted $\mathrm{N}$ 1s photoelectron envelope for the NSCA-700 and NSCA-900 samples are depicted in Fig. S3 and $\mathrm{S} 4, \dagger$ respectively. There are three different peaks in all NSCA samples, which revealed the presence of pyridinic- $\mathrm{N}(398.4 \pm 0.2 \mathrm{eV})$, pyrrolic $\mathrm{N}(399.9 \pm$
$0.2 \mathrm{eV})$, and graphitic-N (401.2 $\pm 0.2 \mathrm{eV})$. Moreover, it could clearly be observed that the relative content of different nitrogen functional groups changes when pyrolysis temperature gradually increases, indicating the impact of temperature dependency on the N-bonding configurations. Interestingly, with the increased pyrolysis temperatures, the pyrrolic $\mathrm{N}$ peak gradually decreases, the graphitic-N peak becomes dominant, suggesting the formation of more graphitic- $\mathrm{N}$ with increasing temperature. ${ }^{35}$ Furthermore, the relative concentration for pyridinic $\mathrm{N}$ in three NSCA samples reached the maximum of 42.2 at $\%$ at $800{ }^{\circ} \mathrm{C}$, which is markedly higher than that of 23.4 at $\%$ at $700{ }^{\circ} \mathrm{C}$ and 36.3 at $\%$ at $900{ }^{\circ} \mathrm{C}$. Owing to the reason known that pyridinic $\mathrm{N}$ plays a crucial role in improving ORR electrocatalytic performance, ${ }^{39}$ it can be reasonably deduced that the ORR performance of NSCA- 800 catalyst will be superior to that of the NSCA-700 and NSCA-900 catalysts.

As shown in Fig. S5, $\dagger$ in order to study the electrocatalytic performance of three NSCA catalysts, electrochemical cyclic voltammetry (CV) measurements were further carried out at the scan rate of $10 \mathrm{mV} \mathrm{s}^{-1}$ in an $\mathrm{Ar}$ or $\mathrm{O}_{2}$ saturated $0.1 \mathrm{M} \mathrm{KOH}$ solution. It can be seen that in the case of Ar saturation, the NSCA-800 catalyst exhibits only a featureless capacitive 
a)

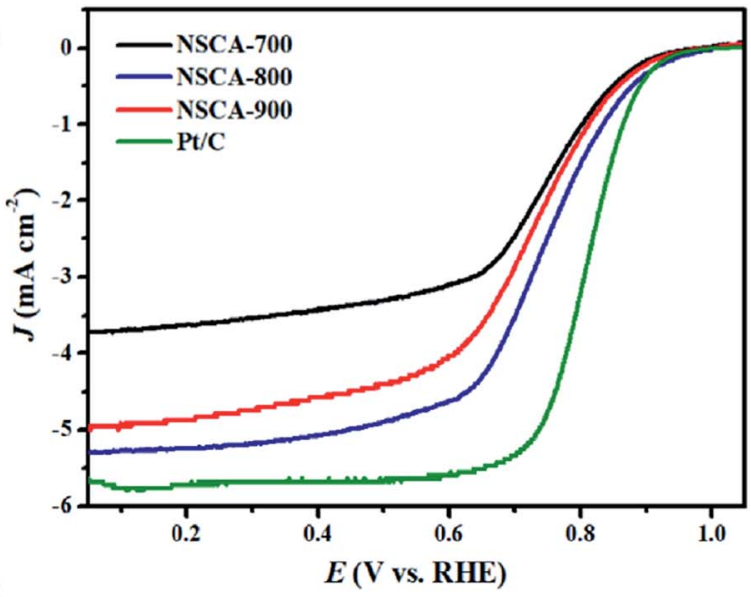

c)

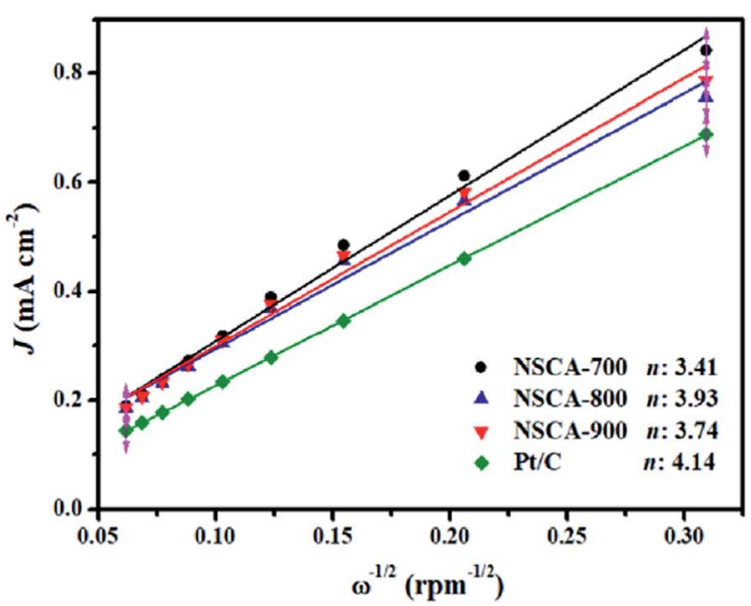

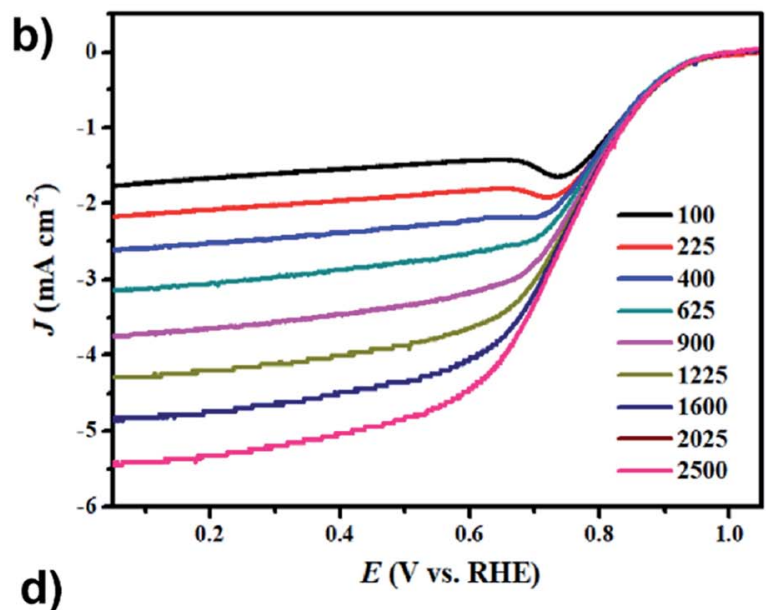

d)

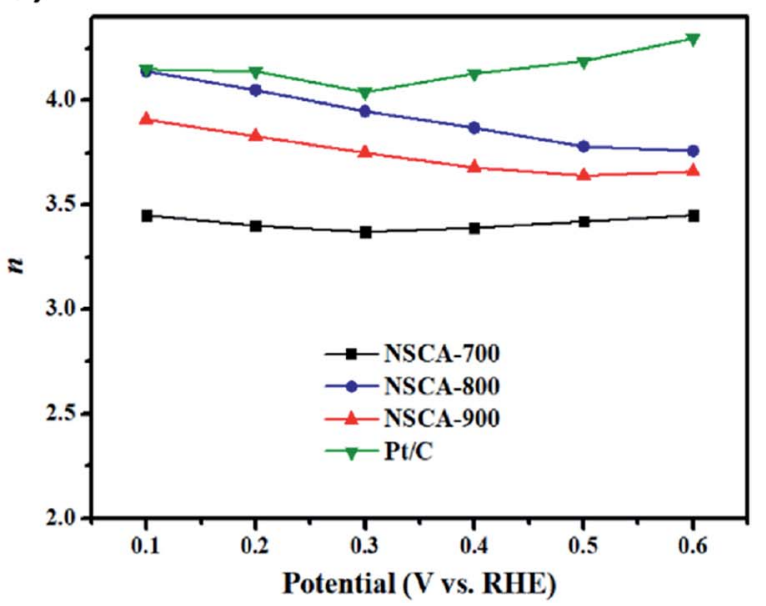

Fig. 4 The ORR performance for catalysts measured in 0.1 M KOH electrolyte. (a) Comparison of LSV curves for NSCA-700, NSCA-800, NSCA900 , and commercial Pt/C catalyst at a rotating speed of $1600 \mathrm{rpm}$ in $\mathrm{O}_{2}$-saturated electrolyte. (b) LSV curves for the NC-800 catalyst at different rotating speeds ranged from 100 to $2500 \mathrm{rpm}$. (c) $\mathrm{K}$ - L plots for the different catalysts based on the LSV curves at different rotation speeds at $0.4 \mathrm{~V}$ (vs. RHE). (d) Electron transfer number ( $n$ ) calculated from the $\mathrm{K}-\mathrm{L}$ plots for the various catalysts in the potential range of $0.1-0.6 \mathrm{~V}$ ( $v s$. RHE).

behavior. However, in $\mathrm{O}_{2}$ saturated $\mathrm{KOH}$ electrolyte, a welldefined cathodic peak originates at $+0.78 \mathrm{~V}$ ( $v s$. RHE), which indicates the prominent electrocatalytic activity. To further understand the ORR kinetics of three NSCA catalysts, linear sweep voltammetry (LSV) measurements were investigated on rotating disk electrode ( $\mathrm{RDE}$ ) at $1600 \mathrm{rpm}$ in $\mathrm{O}_{2}$-saturated $0.1 \mathrm{M}$
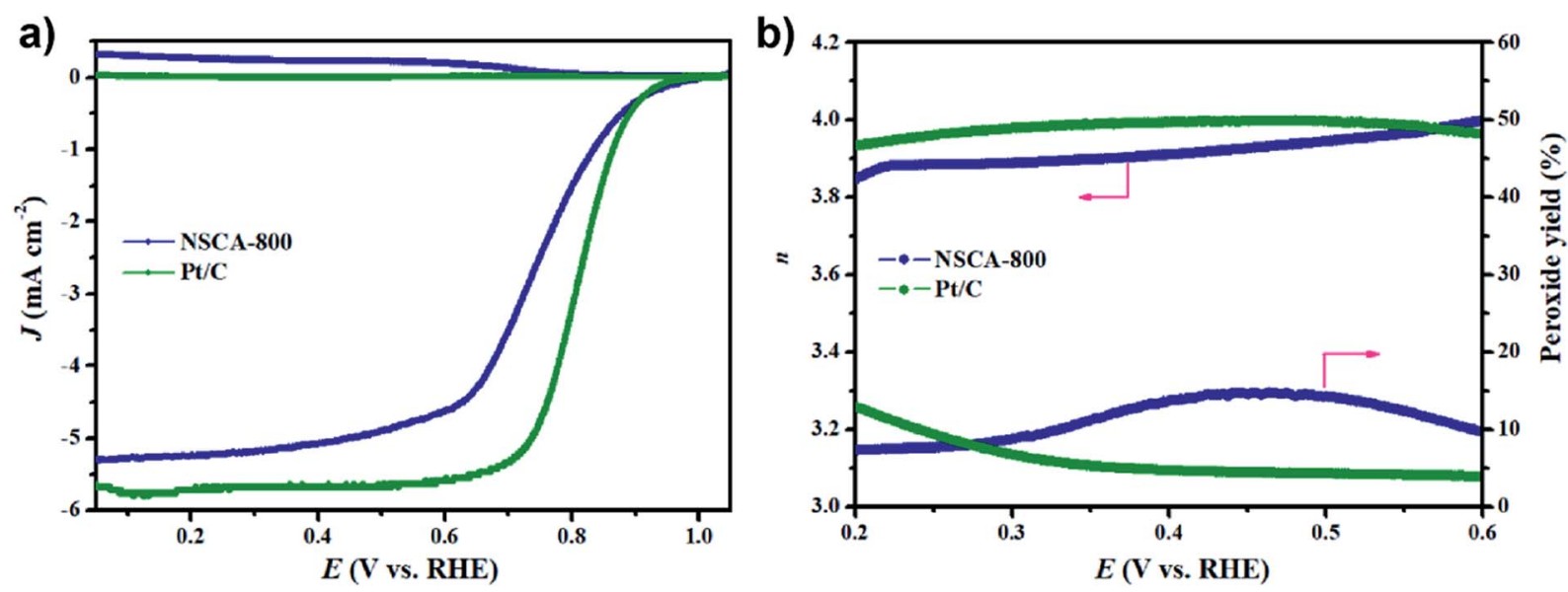

Fig. 5 (a) Rotating ring-disk polarization curves of the NSCA-800 and commercial Pt/C catalyst at rotating speed of $1600 \mathrm{rpm}$ in $\mathrm{O}_{2}$-saturated $0.1 \mathrm{M} \mathrm{KOH}$ electrolyte. (b) Electrons transfer number $(n)$ and peroxide yield of the NSCA- 800 and commercial Pt/C catalyst in $\mathrm{O}_{2}-$ saturated $0.1 \mathrm{M}$ $\mathrm{KOH}$ electrolyte. 
$\mathrm{KOH}$ electrolyte with a sweep rate of $5 \mathrm{mV} \mathrm{s}^{-1}$. As shown in Fig. 4a, the onset potential for the NSCA-800 catalyst is $0.92 \mathrm{~V}$, which is more positive than that of the NSCA-700 $(0.88 \mathrm{~V})$ and NSCA-900 ( $0.90 \mathrm{~V})$ catalyst. As expected, the NSCA-800 catalyst exhibits the best ORR activity among three NSCA catalysts. The enhanced ORR activity for NSCA-800 catalyst could be ascribed to both the relatively high content of nitrogen (5.03 at\%) and the large $S_{\mathrm{BET}}\left(839 \mathrm{~m}^{2} \mathrm{~g}^{-1}\right)$, which could accelerate the mass transfer. So far, the commercial $\mathrm{Pt} / \mathrm{C}$ electrocatalyst is the standard and widespread catalyst for oxygen reduction reaction. Thus, the above LSV results for the NSCA catalysts are compared with those of the commercial $\mathrm{Pt} / \mathrm{C}$ catalyst in order to provide a realistic picture. It is deserved to be mention that the NSCA800 catalyst exhibits comparable onset potential with the $\mathrm{Pt} / \mathrm{C}$ catalyst $(0.93 \mathrm{~V})$. Besides, the dependence of limiting current densities and the half-wave potential $\left(E_{1 / 2}\right)$ of three NSCA catalysts with the different carbonization temperature are illustrated in Fig. S6. $\dagger$ Remarkably, the limiting current density of NSCA-800 catalyst is $5.31 \mathrm{~mA} \mathrm{~cm}{ }^{-2}$, which is much higher than that of NSCA-700 $\left(3.71 \mathrm{~mA} \mathrm{~cm}^{-2}\right)$, and NSCA-900 $\left(4.96 \mathrm{~mA} \mathrm{~cm}^{-2}\right)$ catalyst. Even to be compared with the $\mathrm{Pt} / \mathrm{C}$ catalyst, the onset potential of the NSCA- 800 catalyst is just $17 \mathrm{mV}$ negative, and the limiting current density is slightly lower $\left(5.79 \mathrm{~mA} \mathrm{~cm}^{-2} ; \mathrm{Pt} /\right.$ C). Generally speaking, the most suitable compared standard of electrocatalytic activity for carbon-based catalyst was recognized as the half-wave potential. ${ }^{38}$ As shown in Fig. S6, $\dagger$ the measured half-wave potentials of NSAC-800 catalyst is $0.74 \mathrm{~V}$, which is $72 \mathrm{mV}$ negative than that of $\mathrm{Pt} / \mathrm{C}(0.82 \mathrm{~V})$, similar with other latest reports on carbon electrocatalysts. ${ }^{12,15,19,23,40}$ Overall, as evidenced by the most positive onset potential and highest limiting current density, NSCA-800 shows the best ORR performance among three catalysts. The superior performance could be attributed to the optimized doped nitrogen content, large specific surface area, and abundant structural defects as active sites to adsorb oxygen. It has been reported in the literature that the active sites of $\mathrm{N}$-doped carbon materials are mainly pyridinic $\mathrm{N}$ and graphitic- $\mathrm{N}$ derived from the $\mathrm{N}$ - functional groups, which the pyridinic $\mathrm{N}$ may enhance electrocatalytic activity to some extent. ${ }^{21,41}$

To further explore the reaction pathway of the NSCA-800 catalyst, the RDE measurements with different rotating speeds from 100 to $2500 \mathrm{rpm}$ at a scan rate of $10 \mathrm{mV} \mathrm{s}^{-1}$ were also employed. As depicted in Fig. 4b, it can be obviously seen that the limiting current density increased with increasing rotation rate, indicating a shortened diffusion distance and highly efficient mass transfer, which is ascribed to the abundant mesoporous structure in NSCA-800 catalyst. The diffusion kinetics was investigated by Koutecky-Levich (K-L) plots (Fig. 4e), and the electron transfer numbers $(n)$ of NSCA catalysts were calculated using the $\mathrm{K}-\mathrm{L}$ equation (Fig. 4f). The average $n$ for $\mathrm{NC}-800$ is calculated to be 3.93 approximated to 4 , indicating a predominant $4 \mathrm{e}^{-}$pathway of ORR process. By comparison, the average value of $n$ for NC-700 and NC-900 is calculated to be 3.41 and 3.74, respectively. Additionally, $n$ value for NC-800 is 3.764.14 at the potential range of $0.1-0.6 \mathrm{~V}$ (vs. RHE), clearly larger than that of other two catalysts, which could further signify the importance of high content of doped nitrogen. According to the Dai et al. report, ${ }^{17}$ the oxygen chemisorption mode for carbon materials with nitrogen-free surface belongs to end-on adsorption (Pauling model). However, the doped $\mathrm{N}$ atoms may create a positive charge on the adjacent carbon atoms ascribed to its high electronegativity, which changes chemisorption mode of $\mathrm{O}_{2}$ into side-on adsorption (Yeager model). Therefore, high Ndoping content of both graphitic $\mathrm{N}$ species and pyridinic $\mathrm{N}$ species is crucial for ORR process.

Based on the RRDE measurements (Fig. 5a), we can further confirm the four-electron oxygen reduction process of NSCA-800 catalyst (Fig. 5b). The electrons transfer number at a potential ranged from 0.2 to $0.6 \mathrm{~V}$ ( $v s$. RHE) is calculated to be 3.9 , which is highly consistent with the value (3.93) calculated by the $\mathrm{K}-\mathrm{L}$ equation. Besides, the average peroxide yield from the ring electrode is calculated to be $10 \%$, which is slightly higher than the value of the commercial Pt/C catalyst (6.7\%). In brief, the RRDE results have further implied that the ORR process
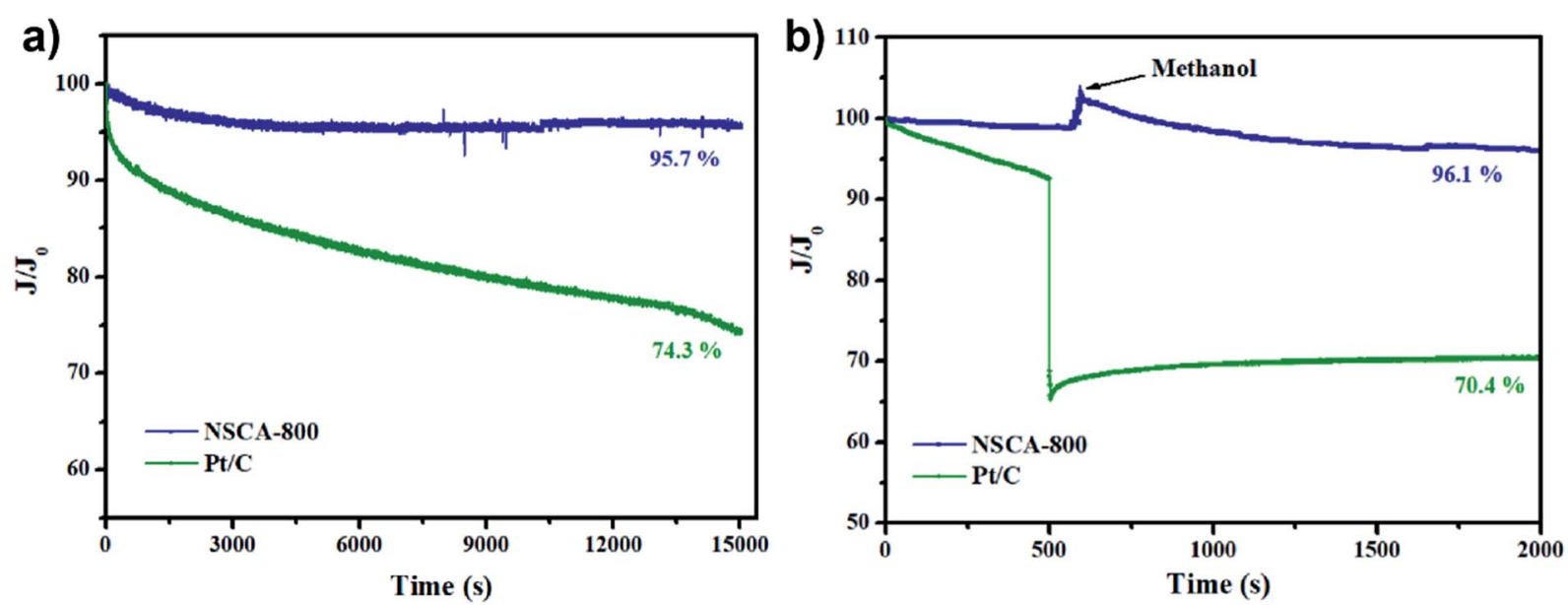

Fig. 6 (a) Chronoamperometric curves for NSCA-800 and commercial Pt/C catalysts at $0.4 \mathrm{~V}$ (vs. RHE) in $\mathrm{O}_{2}$-saturated $0.1 \mathrm{M} \mathrm{KOH}$ electrolyte. (b) Chronoamperometric curves in response to methanol-crossover in $\mathrm{O}_{2}$-saturated $0.1 \mathrm{M} \mathrm{KOH}$ electrolyte. 
catalyzed by NSCA-800 catalyst is a dominant four-electron process, rather than a two-electron reaction pathway. Notably, the peroxides are main products via two-electron process, which could corrode the proton exchange membrane and the catalyst layer, resulting in the fuel cell poisoned.

The long-term operation stability of ORR electrocatalysts is also crucial factor for their practical applications, such as fuel cells or metal-air batteries. Therefore, the current-time $(i-t)$ tests were measured in $\mathrm{O}_{2}$-saturated $0.1 \mathrm{M} \mathrm{KOH}$ electrolyte on RDE electrode with rotating speed of $1600 \mathrm{rpm}$, and the durability curve is demonstrated in Fig. 6a. Notably, the NSCA-800 catalyst only exhibited a slight decrease $(4.3 \%)$ while remaining $95.7 \%$ of the ORR kinetic current after continuous $4 \mathrm{~h}$ test. Unfortunately, the commercial $\mathrm{Pt} / \mathrm{C}$ catalyst suffers a drastic $25.7 \%$ degradation, probably because of the migration and deactivation of Pt nanoparticles as well as their detachment from the carbon matrix during continuous operation. ${ }^{34}$ Furthermore, as shown in Fig. 6b, the methanol tolerance was performed. As expected, the current curve for NSCA-800 exhibits negligible change after adding methanol, while the commercial $\mathrm{Pt} / \mathrm{C}$ has a dramatical decline, suggesting that NSCA-800 has better methanol tolerance than that of Pt/C. Obviously, the asprepared NSCA-800 catalyst shows superior oxygen reduction reaction stability and methanol tolerance to the $\mathrm{Pt} / \mathrm{C}$ in alkaline medium, which could be ascribed to the stable N-relative active sites and strong metal-free porous architecture. Therefore, the biomass gelatin based 3D inter-connected nitrogen self-doped carbon products could be a promising ORR electrocatalyst for practical application in fuel cells or metal-air batteries.

\section{Conclusions}

In summary, we report a facile, environmental friendly and sacrificial templating method for the preparation of nitrogenself-doped carbon aerogels derived from biomass gelatin with no activation. The $\mathrm{NaCl}$ sacrificial template was used to produce a three-dimensional interconnected porous structure with large surface area. The self-contained nitrogen in biomass gelatin precursor via pyrolysis process could produce high content of pyridine $\mathrm{N}$ and graphitic-N species, which could promote the electrocatalytic activity for ORR. The as-prepared NSCA-800 catalyst carbonized at $800{ }^{\circ} \mathrm{C}$ demonstrates the best electrocatalytic activity, favorable kinetics and additionally outstanding long-term stability among three as-prepared samples. This facile method to fabricate nitrogen-self-doped carbon catalyst is easy-to-prepare and toxic-free. Thus, this work exhibits a promising approach to design and fabricate a highly efficient and durable N-doped carbon catalyst by using animal-waste derived biomass materials for highly efficient oxygen reduction reaction.

\section{Conflicts of interest}

There are no conflicts to declare.

\section{Acknowledgements}

This study was financially supported by the National Natural Science Foundation of China (51605188, 51605187, 51607010 and 21673098), Department of Education of Jilin Province (JJKH20180093KJ, JJKH20181163KJ and JJKH20180160KJ), Program for JLU Science and Technology Innovative Research Team and the Joint Program of Jilin Province and JLU (SXGJQY2017-1 and SXGJSF2017-2), Key Scientific \& Technological Research \& Development Projects in Jilin Province (Grant No. 20180201038GX).

\section{References}

1 M. K. Debe, Nature, 2012, 486, 43-51.

2 W. Xiong, F. Du, Y. Liu, A. Perez, M. Supp, T. S. Ramakrishnan, L. Dai and L. Jiang, J. Am. Chem. Soc., 2010, 132, 15839-15841.

3 G. Jo, J. Sanetuntikul and S. Shanmugam, RSC Adv., 2015, 5, 53637-53643.

4 X. X. Wang, D. A. Cullen, Y. T. Pan, S. Hwang, M. Wang, Z. Feng, J. Wang, M. H. Engelhard, H. Zhang, Y. He, Y. Shao, D. Su, K. L. More, J. S. Spendelow and G. Wu, Adv. Mater., 2018, 30, 1706758.

5 L. Xue, Y. Li, X. Liu, Q. Liu, J. Shang, H. Duan, L. Dai and J. Shui, Nat. Commun., 2018, 9, 3819.

6 Y. Li, Y. Li, E. Zhu, T. McLouth, C. Y. Chiu, X. Huang and Y. Huang, J. Am. Chem. Soc., 2012, 134, 12326-12329.

7 B. Y. Xia, Y. Yan, N. Li, H. B. Wu, X. W. Lou and X. Wang, Nat. Energy, 2016, 1, 15006.

8 Y. J. Wang, N. Zhao, B. Fang, H. Li, X. T. Bi and H. Wang, Chem. Rev., 2015, 115, 3433-3467.

9 S. Brüller, H.-W. Liang, U. I. Kramm, J. W. Krumpfer, X. Feng and K. Müllen, J. Mater. Chem. A, 2015, 3, 23799-23808.

10 N. R. Sahraie, U. I. Kramm, J. Steinberg, Y. Zhang, A. Thomas, T. Reier, J. P. Paraknowitsch and P. Strasser, Nat. Commun., 2015, 6, 8618.

11 J. Zhang, Z. Zhao, Z. Xia and L. Dai, Nat. Nanotechnol., 2015, 10, 444-452.

12 C. Hu and L. Dai, Adv. Mater., 2017, 29, 1604942.

13 M. Vikkisk, I. Kruusenberg, S. Ratso, U. Joost, E. Shulga, I. Kink, P. Rauwel and K. Tammeveski, RSC Adv., 2015, 5, 59495-59505.

14 A. A. Ensafi, M. Jafari-Asl and B. Rezaei, Electrochim. Acta, 2016, 194, 95-103.

15 H.-W. Liang, Z.-Y. Wu, L.-F. Chen, C. Li and S.-H. Yu, Nano Energy, 2015, 11, 366-376.

16 W. Yang, X. Liu, X. Yue, J. Jia and S. Guo, J. Am. Chem. Soc., 2015, 137, 1436-1439.

17 G. Kuanping, D. Feng, X. Zhenhai, D. Michael and D. Liming, Science, 2009, 323, 760-764.

18 B. Nagy, S. Villar-Rodil, J. Tascón, I. Bakos and K. László, Microporous Mesoporous Mater., 2016, 230, 135-144.

19 J. Shui, M. Wang, F. Du and L. Dai, Sci. Adv., 2015, 1, e1400129.

20 M. Justus, X. Wei, M. Martin and S. Wolfgang, Angew. Chem., Int. Ed., 2015, 54, 10102-10120. 
21 D. Geng, Y. Chen, Y. Chen, Y. Li, R. Li, X. Sun, S. Ye and S. Knights, Energy Environ. Sci., 2011, 4, 760.

22 Z. Liu, Z. Li, J. Ma, X. Dong, W. Ku, M. Wang, H. Sun, S. Liang and G. Lu, Energy, 2018, 162, 453-459.

23 F. Pan, Z. Cao, Q. Zhao, H. Liang and J. Zhang, J. Power Sources, 2014, 272, 8-15.

24 M. K. Rybarczyk, M. Lieder and M. Jablonska, RSC Adv., 2015, 5, 44969-44977.

25 M. Borghei, N. Laocharoen, E. Kibena-Põldsepp, L.-S. Johansson, J. Campbell, E. Kauppinen, K. Tammeveski and O. J. Rojas, Appl. Catal., B, 2017, 204, 394-402.

26 Q. Liu, Y. Zhou, S. Chen, Z. Wang, H. Hou and F. Zhao, J. Power Sources, 2015, 273, 1189-1193.

27 J. Maruyama, J. Okamura, K. Miyazaki, Y. Uchimoto and I. Abe, J. Phys. Chem. C, 2008, 112, 2784-2790.

28 J. Zheng, C. Guo, C. Chen, M. Fan, J. Gong, Y. Zhang, T. Zhao, Y. Sun, X. Xu, M. Li, R. Wang, Z. Luo and C. Chen, Electrochim. Acta, 2015, 168, 386-393.

29 W. Zhong-Li, X. Dan, Z. Hai-Xia, W. Jun, M. Fan-Lu and Z. Xin-Bo, Sci. Adv., 2015, 1, e1400035.

30 J. Niu, M. Liu, F. Xu, Z. Zhang, M. Dou and F. Wang, Carbon, 2018, 140, 664-672.

31 N. Wang, T. Li, Y. Song, J. Liu and F. Wang, Carbon, 2018, 130, 692-700.
32 Y. Hao, X. Zhang, Q. Yang, K. Chen, J. Guo, D. Zhou, L. Feng and Z. Slanina, Carbon, 2018, 137, 93-103.

33 S. Fu, C. Zhu, J. Song, M. Engelhard, B. Xiao, D. Du and Y. Lin, Chemistry, 2017, 23, 10460-10464.

34 K. Yuan, C. Lu, S. Sfaelou, X. Liao, X. Zhuang, Y. Chen, U. Scherf and X. Feng, Nano Energy, 2019, 59, 207-215.

35 S. Gao, K. Geng, H. Liu, X. Wei, M. Zhang, P. Wang and J. Wang, Energy Environ. Sci., 2015, 8, 221-229.

36 W. Ding, Z. Wei, S. Chen, X. Qi, T. Yang, J. Hu, D. Wang, L. J. Wan, S. F. Alvi and L. Li, Angew. Chem., Int. Ed., 2013, 52, 11755-11759.

37 H. Yu, L. Shang, T. Bian, R. Shi, G. I. Waterhouse, Y. Zhao, C. Zhou, L. Z. Wu, C. H. Tung and T. Zhang, Adv. Mater., 2016, 28, 5080-5086.

38 H. Deng, Q. Li, J. Liu and F. Wang, Carbon, 2017, 112, 219229.

39 L. Lai, J. R. Potts, D. Zhan, L. Wang, C. K. Poh, C. Tang, H. Gong, Z. Shen, J. Lin and R. S. Ruoff, Energy Environ. Sci., 2012, 5, 7936.

40 M. Zhang, X. Jin, L. Wang, M. Sun, Y. Tang, Y. Chen, Y. Sun, X. Yang and P. Wan, Appl. Surf. Sci., 2017, 411, 251-260.

41 G. Liu, X. Li, J.-W. Lee and B. N. Popov, Catal. Sci. Technol., 2011, 1, 207. 